\title{
Structure of nanocomposites of Al-Fe alloys prepared by mechanical alloying and rapid solidification processing
}

\author{
S S NAYAK ${ }^{\dagger}$, B S MURTY ${ }^{\dagger \dagger}$ and S K PABI* \\ Department of Metallurgical and Materials Engineering, Indian Institute of Technology, Kharagpur 721 302, India \\ ${ }^{\dagger}$ Presently a Research Associate at the University of Louisiana at Lafayette, Lafayette 70504, Louisiana, USA \\ ${ }^{\dagger \dagger}$ Department of Metallurgical and Materials Engineering, Indian Institute of Technology Madras, Chennai 600036 , \\ India
}

\begin{abstract}
Structures of Al-based nanocomposites of Al-Fe alloys prepared by mechanical alloying (MA) and subsequent annealing are compared with those obtained by rapid solidification processing (RSP). MA produced only supersaturated solid solution of $\mathrm{Fe}$ in $\mathrm{Al}$ up to 10 at. \% Fe, while for higher Fe content up to 20 at. \% the nonequilibrium intermetallic $\mathrm{Al}_{5} \mathrm{Fe}_{2}$ appeared. Subsequent annealing at $673 \mathrm{~K}$ resulted in more $\mathrm{Al}_{5} \mathrm{Fe}_{2}$ formation with very little coarsening. The equilibrium intermetallics, $\mathrm{Al}_{3} \mathrm{Fe}\left(\mathrm{Al}_{13} \mathrm{Fe}_{4}\right)$, was not observed even at this temperature. In contrast, ribbons of similar composition produced by RSP formed fine cellular or dendritic structure with nanosized dispersoids of possibly a nano-quasicrystalline phase and amorphous phase along with $\alpha$-Al depending on the Fe content in the alloys. This difference in the product structure can be attributed to the difference in alloying mechanisms in MA and RSP.
\end{abstract}

Keywords. Nanocomposites; Al-Fe; mechanical alloying; rapid solidification; quasicrystalline.

\section{Introduction}

Al-Fe alloys are attractive for applications at temperatures beyond those normally associated with the conventional aluminum alloys. Alloying $\mathrm{Al}$ with $\mathrm{Fe}$ increases the high temperature strength due to the dispersion of secondphase particles (Froes et al 2001). Unfortunately, the equilibrium solubility of $\mathrm{Fe}$ in the Al lattice is very low, and it does not exceed $0.03 \%$ (All the compositions are in atomic \% unless otherwise stated) (Kattner 1986). Hence, these alloys cannot be precipitation strengthened by conventional ageing treatments. The strengthening effect can be enhanced by increasing the solid solubility of $\mathrm{Fe}$ in the Al matrix by some nonequilibrium processing techniques, viz. rapid solidification processing (RSP) (Tonejc and Bonefasčić 1969; Young and Cline 1981; Riontino and Zanada 1994; Badan et al 1996), mechanical alloying (MA) (Huang et al 1990; Niu et al 1994; Mukhopadhyay et al 1995; Fadeeva and Leonov 1996; Kaloshkin et al 2002) and severe plastic deformation (SPD) (Senkov et al 1998). These non-equilibrium processing techniques can refine the microstructure of metals and alloys up to nanometer-level, and lead to the formation of metastable phases including supersaturated solid solutions. These novel constitutional and microstructural effects can enhance the physical and mechanical properties.

\footnotetext{
*Author for correspondence (skpabi@metal.iitkgp.ernet.in)
}

RSP, MA and SPD have been reported as tools for extension of Fe solubility in $\mathrm{Al}$, so that the resultant supersaturated solid solution can lead to the formation of nanocrystalline precipitation strengthened structure after aging (Froes et al 2001). In particular, MA and RSP of metallic alloys of many systems lead to the formation of materials with unique combination of advantageous properties, which are determined by the novel features of the microstructure and crystal structure of the alloys. No systematic comparison of the structure and morphology of the phases formed by MA and RSP in the Al-rich Al-Fe alloys of similar composition have been reported, so far. The present work attempts to fill this gap reporting a comparison of the structures of nanocomposites of $\mathrm{Al}-\mathrm{Fe}$ alloys prepared by MA and subsequent annealing with those generated by RSP. This is of particular interest for the development of nanocomposites of this alloy system for high strength applications.

\section{Experimental}

\subsection{Mechanical alloying (MA)}

MA of Al-Fe alloys with nominal composition, $\mathrm{Al}_{100-x} \mathrm{Fe}_{x}$, for $x=2 \cdot 5,5,10,15$ and 20, was carried out using high purity powders of $\mathrm{Al}(99.9 \mathrm{wt} . \%)$ and $\mathrm{Fe}(99.98 \mathrm{wt} \%$ ) as the starting materials. Elemental powder blends of desired nominal composition were ball milled in a high energy Fritsch Pulverisette-5 planetary ball mill in cemented 
carbide grinding media at a mill speed of $300 \mathrm{rpm}$ and ball to powder ratio $10: 1$, using toluene as the process control agent. The as-milled powder samples were characterized by X-ray diffraction (XRD) for the phase identification and crystallite size measurements using the $\mathrm{Co}-\mathrm{K} \alpha$ radiation in a PHILIPS 1719 diffractometer. The effective crystallite size was calculated from the line profile analysis of $\mathrm{Al}(111)$ peak, recorded using Co$\mathrm{K} \alpha$ radiation, by the Voigt's equation after eliminating contribution of instrumental broadening as reported earlier (De Keijser et al 1982; Datta et al 2000a). The enthalpy of formation $\left(\Delta H_{\mathrm{f}}\right)$ of $\mathrm{Al}-\mathrm{Fe}$ alloys was calculated through Miedema's semiempirical model (De Boer et al 1989).

Nanocrystalline Al-Fe alloy powders after MA were consolidated into cylindrical pellets of $12 \mathrm{~mm}$ diameter under a load of $375 \mathrm{MPa}$ for $15 \mathrm{~s}$ using an INSMART uniaxial hydraulic press. The density of the pellets was measured by the Archimedes' principle using the Sartorius density measurement kit. The consolidated pellets were characterized by PHILIPS X'pert Pro high resolution XRD using $\mathrm{Cu}-\mathrm{K} \alpha$ radiation for phase analysis. Microstructural analysis of the consolidated pellets was carried out by means of a PHILIPS CM30 transmission electron microscope (TEM) operated at $300 \mathrm{kV}$. For electron transparency, thin-foil specimens were mechanically polished and subsequently ion beam milled.

\subsection{Rapid solidification processing (RSP)}

Binary alloys of nominal compositions similar to those used in MA (see $\$ 2.1$ ), i.e. Al-2.5, 5, 10, 15 and $20 \% \mathrm{Fe}$ were prepared by melting appropriate amounts of high purity, Al (99.96\%) and $\mathrm{Fe}(99.98 \%)$, under argon atmosphere in a high-frequency induction furnace. Melting of the alloys was carried out in a graphite crucible coated with boron nitride on its inner surface in order to minimize the contamination in the master alloys during melting. RSP of the molten alloys was carried out by a singleroller melt spinner with copper wheel of $300 \mathrm{~mm}$ diameter at different linear wheel speeds, viz. $20 \mathrm{~m} / \mathrm{s}, 30 \mathrm{~m} / \mathrm{s}$ and $40 \mathrm{~m} / \mathrm{s}$. The cooling rates were estimated to be in the range of $10^{4}-10^{5} \mathrm{~K} / \mathrm{s}$. The melt-spun ribbons were about $1.5-3 \mathrm{~mm}$ wide and $25-100 \mu \mathrm{m}$ thick. The structural characterization of the as-spun alloys was carried out by $\mathrm{XRD}$ in a Rikagu CN-2301 diffractometer for the phase identification and lattice parameter measurements using monochromatic $\mathrm{Cu}-\mathrm{K} \alpha$ radiation. TEM of the melt-spun alloys was carried out for observing the microstructure and recording electron diffraction pattern using a JEOL 2000 FXII transmission electron microscope equipped with a Link energy-dispersive X-ray spectroscope. For electron transparency, the thin-foil specimens were prepared by ion beam milling.

\section{Results and discussion}

\subsection{Nanocomposites produced by $M A$}

XRD analysis of all the compositions studied in the present work formed supersaturated solid solution of $\mathrm{Fe}$ in $\mathrm{Al}$, i.e. $\mathrm{Al}(\mathrm{Fe})$ after $20 \mathrm{~h}$ of MA, except in the case of $\mathrm{Al}-$ $20 \% \mathrm{Fe}$ alloy that formed the metastable $\mathrm{Al}_{5} \mathrm{Fe}_{2}$ intermetallic along with $\mathrm{Al}(\mathrm{Fe})$, as shown in figure 1(a). It was observed from these XRD patterns that after $20 \mathrm{~h}$ of MA, the intensity of $\mathrm{Al}(111)$ peak continuously decreased with concurrent increase in the peak width with $\mathrm{Fe}$ enrichment in the alloys. An increase in the XRD peak widths following milling under identical conditions increased with Fe content in the alloy, which indicated enhanced crystal size refinement during MA with $\mathrm{Fe}$ addition. This was confirmed from the variation of crystallite size of Al with Fe content in the alloy (figure 1(b)). The crystallite size after $20 \mathrm{~h}$ of MA was highest $(27 \mathrm{~nm})$ in the $\mathrm{Al}-2.5 \% \mathrm{Fe}$ alloy while a minimum crystallite size of $9 \mathrm{~nm}$ was measured for $\mathrm{Al}-20 \% \mathrm{Fe}$ alloy. Precise lattice parameter estimated from the patterns in figure 1(a) evidenced a shift of the $\mathrm{Al}(111)$ peak to higher diffraction angle with the increase in $\mathrm{Fe}$ content in the alloy up to $10 \% \mathrm{Fe}$ (figure $1(b))$, and this suggested the incorporation of more $\mathrm{Fe}$ atoms $(0.124 \mathrm{~nm}$ dia.) into $\mathrm{Al}(0.143 \mathrm{~nm}$ dia.) lattice. However, beyond $10 \% \mathrm{Fe}$ the lattice parameter variation manifested a discontinuity and an increase with the addition of Fe (cf. for 15 and $20 \% \mathrm{Fe}$ in figure 1(b)), possibly evidencing the formation of a new phase.

While the intensity of $\mathrm{Al}(111)$ peak was found to decrease with increase in $\mathrm{Fe}$ content in the alloys, that of $\mathrm{Al}(200)$ peak increased and shifted to lower diffraction angle. In fact, $\mathrm{Al}-20 \% \mathrm{Fe}$ alloy after $20 \mathrm{~h}$ of MA was found to form a broad peak in the diffraction angle range 50-54 degree, and another shoulder peak was seen close to it indicating the contribution of another phase to the intensity of this peak (figure 1(a)). To ascertain the phases present in $\mathrm{Al}-20 \% \mathrm{Fe}$, the $\mathrm{Al}(200)$ peak profile was subjected to deconvolution, which is shown in figure 1(c). After this deconvolution, $\mathrm{Al}(200)$ and $\mathrm{Al}_{5} \mathrm{Fe}_{2}(311)$ peaks were identified, however, the intensity of the $\mathrm{Al}(200)$ peak was low. The reason for decrease in $\mathrm{Al}(111)$ peak is the formation of more amounts of $\mathrm{Al}_{5} \mathrm{~F}_{2}$ intermetallic during MA as the composition reached closer to its stoichiometric composition. The increase in intensity of $\mathrm{Al}(200)$ peak is attributed to overlapping of diffraction angle of $\mathrm{Al}(200)$ peak, $\mathrm{Fe}(110)$ peak from any undissolved $\mathrm{Fe}$, as well as, of the $\mathrm{Al}_{5} \mathrm{~F}_{2}$ (311) peak, so that they all contribute to form a broad peak due to the finer crystallite size after $20 \mathrm{~h}$ of MA. The intensity ratio of $\mathrm{Al}(200)$ peak in said deconvoluted pattern decreased with the increase in the Fe content in the alloy, suggesting the formation of $\mathrm{Al}_{5} \mathrm{~F}_{2}$ intermetallic phase at the expense of $\mathrm{Al}$ (Nayak et al 2006; Nayak 2007). 

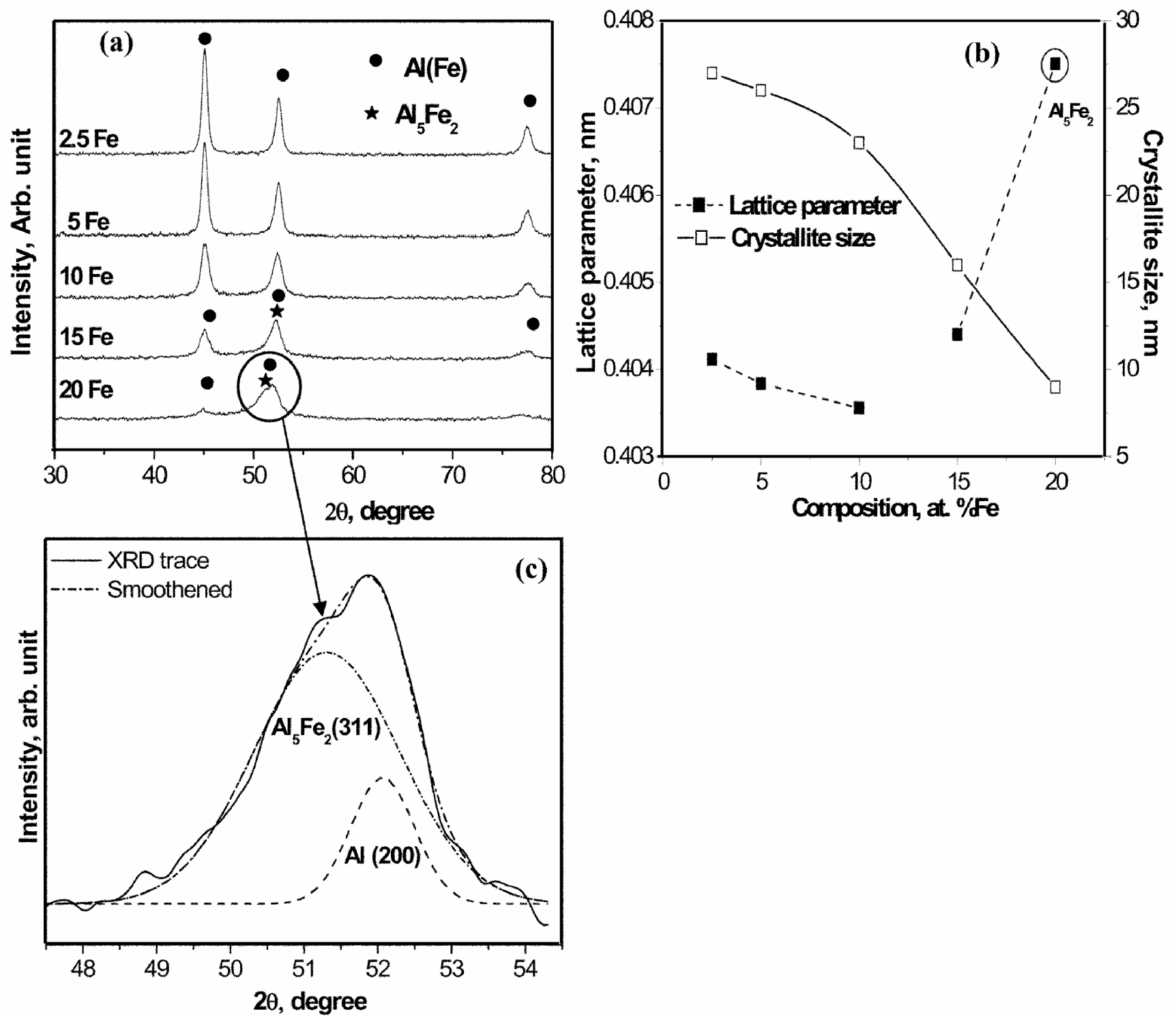

Figure 1. (a) XRD patterns of Al-Fe alloys after $20 \mathrm{~h} \mathrm{MA}$, (b) variation of lattice parameter and crystallite size as a function of $\mathrm{Fe}$ content in $\mathrm{Al}-\mathrm{Fe}$ alloys estimated from patterns in (a). The encircled peak of $\mathrm{Al}-20 \% \mathrm{Fe}$ alloy in (a) deconvoluted in (c) to show presence of $\mathrm{Al}_{5} \mathrm{Fe}_{2}(311)$ and $\mathrm{Al}(200)$ in $\mathrm{Al}-20 \% \mathrm{Fe}$ after $20 \mathrm{~h} \mathrm{MA}$.

According to the phase diagram (Kattner 1986), all the alloy compositions studied in the present work should contain $\mathrm{Al}$ and $\mathrm{Al}_{3} \mathrm{Fe}$ phases under equilibrium. It is interesting to note from figure 1 that under the present $\mathrm{MA}$ conditions, formation of $\mathrm{Al}_{5} \mathrm{Fe}_{2}$ intermetallic prevailed over the synthesis of equilibrium $\mathrm{Al}_{3} \mathrm{Fe}$ phase in $\mathrm{Al}-20$ $\% \mathrm{Fe}$ alloy, which had a composition away from the stoichiometric composition of $\mathrm{Al}_{3} \mathrm{Fe}$. The reason for preferred formation of $\mathrm{Al}_{5} \mathrm{Fe}_{2}$ intermetallic can be attributed to the non-equilibrium nature of the MA process. The enthalpy of formation of $\mathrm{Al}_{5} \mathrm{Fe}_{2}\left(\Delta H_{\mathrm{f}}=-28 \cdot 1 \mathrm{~kJ} / \mathrm{mol}\right)$ and $\mathrm{Al}_{3} \mathrm{Fe} \quad\left(\Delta H_{\mathrm{f}}=-28.26 \mathrm{~kJ} / \mathrm{mol}\right) \quad$ calculated through the Miedema's semi-empirical model (De Boer et al 1989) are similar. Therefore, it is plausible that unlike $\mathrm{Al}_{3} \mathrm{Fe}$, the $\mathrm{Al}_{5} \mathrm{Fe}_{2}$ being a congruent melting compound in the equilibrium diagram (Kattner 1986), is easier to form during MA or subsequent annealing (Datta et al 2000b). From the metastable phase diagram of the $\mathrm{Al}-\mathrm{Fe}$ reported by other investigators (Adam and Hogan 1972; Fadeeva and Leonov 1996), the alloys containing more than $15 \% \mathrm{Fe}$ are expected to contain some $\mathrm{Al}_{6} \mathrm{Fe}$ phase. In the present work, the formation of this metastable phase was also not observed, besides the formation of $\mathrm{Al}_{3} \mathrm{Fe}$ being suppressed, which can be attributed to the large deviation from equilibrium during the MA process.

Figure 1(b) shows that beyond $10 \%$ Fe the lattice parameter increased sharply giving a high value of $0.40751 \mathrm{~nm}$ in case of $\mathrm{Al}-20 \% \mathrm{Fe}$, as marked by circle in the figure. 

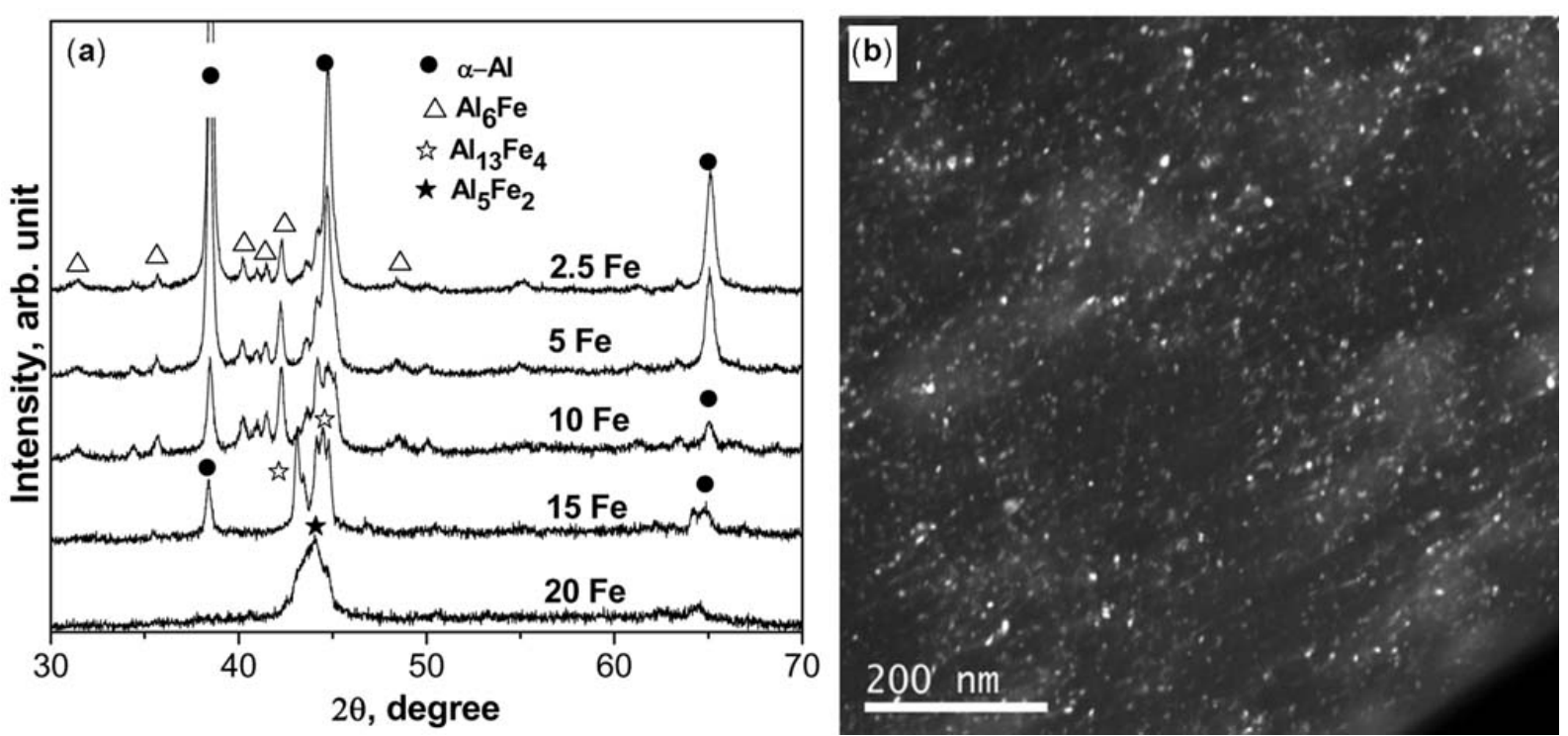

Figure 2. (a) XRD patterns of consolidated nanocrystalline $\mathrm{Al}-\mathrm{Fe}$ alloys after annealing for $2 \mathrm{~h}$ at $673 \mathrm{~K}$ and (b) dark field image of Al-20\%Fe nanocrystalline powder after annealing at $673 \mathrm{~K}$ for $2 \mathrm{~h}$.

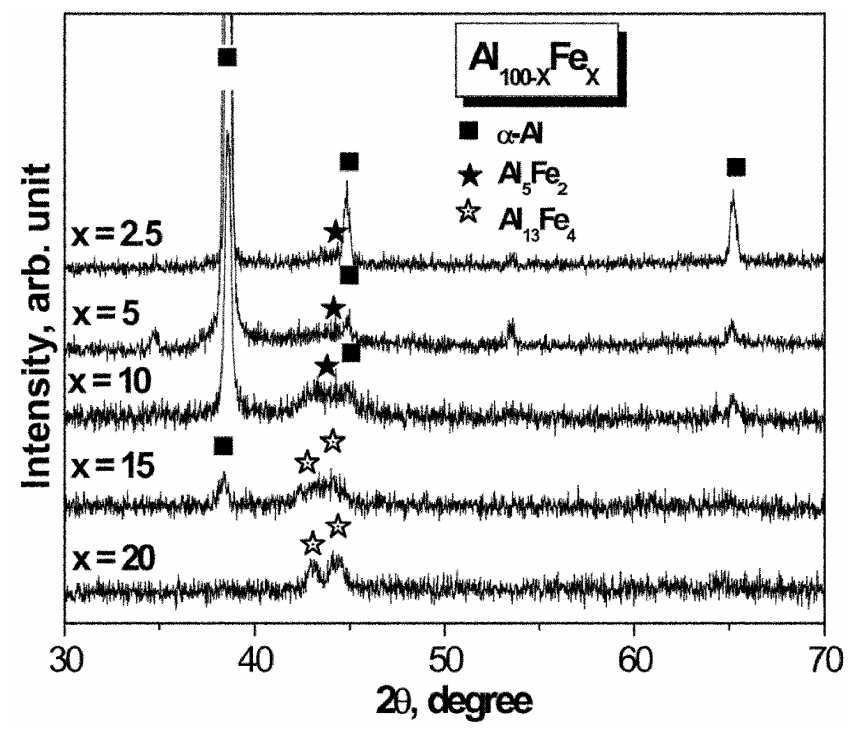

Figure 3. XRD patterns of $\mathrm{Al}_{100-x} \mathrm{Fe}_{x}$ alloys $(x=2 \cdot 5,5,10,15$ and 20) melt spun at a linear wheel speed of $40 \mathrm{~m} / \mathrm{s}$.

Almost a single phase intermetallic $\mathrm{Al}_{5} \mathrm{~F}_{2}$ formed in $\mathrm{Al}-$ $20 \% \mathrm{Fe}$ alloy, which made the powder particle more brittle resulting in extreme refinement of the crystallites $(9 \mathrm{~nm})$ in this particular composition.

Annealing of the nanocrystalline dilute Al-Fe alloys containing $2 \cdot 5-20 \% \mathrm{Fe}$ for $2 \mathrm{~h}$ at $673 \mathrm{~K}$ resulted in the formation of intermetallic phases along with the supersaturated solid solution of $\alpha-\mathrm{Al}$, as shown in the XRD patterns in figure 2(a). The type of intermetallic formed was found to be dependent on the $\mathrm{Fe}$ content, changing from $\mathrm{Al}_{6} \mathrm{Fe}$ at 2.5-10 $\mathrm{Fe}$ to $\mathrm{Al}_{13} \mathrm{Fe}_{4}$ at $15 \% \mathrm{Fe}$, while the formation of $\mathrm{Al}_{5} \mathrm{Fe}_{2}$ possibly with some amount of amorphous phase was apparent only in the $20 \% \mathrm{Fe}$ composition. It may be recalled that after $\mathrm{MA}$ of $\mathrm{Al}-20 \% \mathrm{Fe}$ alloy for $20 \mathrm{~h}$ predominantly $\mathrm{Al}_{5} \mathrm{~F}_{2}$ intermetallic was observed along with very small volume fraction of $\alpha$-Al (figure $1(\mathrm{c})$ ). The dark field image of the $\mathrm{Al}-20 \% \mathrm{Fe}$ nanocomposite powders after annealing at $673 \mathrm{~K}$ for $2 \mathrm{~h}$ confirmed the presence of bright nanocrystalline intermetallic particles as shown in figure 2(b). Here the grain size of ultrafine intermetallic was measured to be around 15-20 nm indicating negligible grain growth from the starting size of $9 \mathrm{~nm}$ even after annealing at $673 \mathrm{~K}$. It also confirmed the formation of nanocomposites of $\mathrm{Al}$ with metastable $\mathrm{Al}_{5} \mathrm{Fe}_{2}$ intermetallic in $\mathrm{Al}-20 \% \mathrm{Fe}$ alloy by MA and subsequent annealing at $673 \mathrm{~K}$ for $2 \mathrm{~h}$.

\subsection{Nanocomposites produced by RSP}

Figure 3 shows the XRD patterns of $\mathrm{Al}_{100-x} \mathrm{Fe}_{x}(x=2 \cdot 5,5$, 10,15 and 20) alloys melt spun at a linear wheel speed of $40 \mathrm{~m} / \mathrm{s}$. The Al-2.5\%Fe melt spun alloy was mostly single phase supersaturated solid solution of $\mathrm{Fe}$ in $\mathrm{Al}$, as evident from the XRD pattern. The $\mathrm{Al}_{5} \mathrm{Fe}_{2}$ intermetallic appeared to be the second phase in $\mathrm{Al}-2 \cdot 5 \%, \mathrm{Al}-5 \% \mathrm{Fe}$ and $\mathrm{Al}-$ $10 \% \mathrm{Fe}$ alloys. The most intense diffraction peak (311) of $\mathrm{Al}_{5} \mathrm{Fe}_{2}$ intermetallic phase was found at $2 \theta=43.79 \mathrm{de}-$ gree, which was quite close to Al (200) diffraction peak (44.73 degree) and hence, it was difficult to distinguish them in the patterns. In case of $\mathrm{Al}-15 \% \mathrm{Fe}$ alloy, the $\mathrm{XRD}$ peaks could be indexed as $\alpha-\mathrm{Al}$ and $\mathrm{Al}_{13} \mathrm{Fe}_{4}$ phases, as shown in the patterns; while mostly single phase $\mathrm{Al}_{13} \mathrm{Fe}_{4}$ intermetallic was found in as melt spun $\mathrm{Al}-20 \% \mathrm{Fe}$ alloy. The volume fraction of $\mathrm{Al}_{13} \mathrm{Fe}_{4}$ increases with in- 

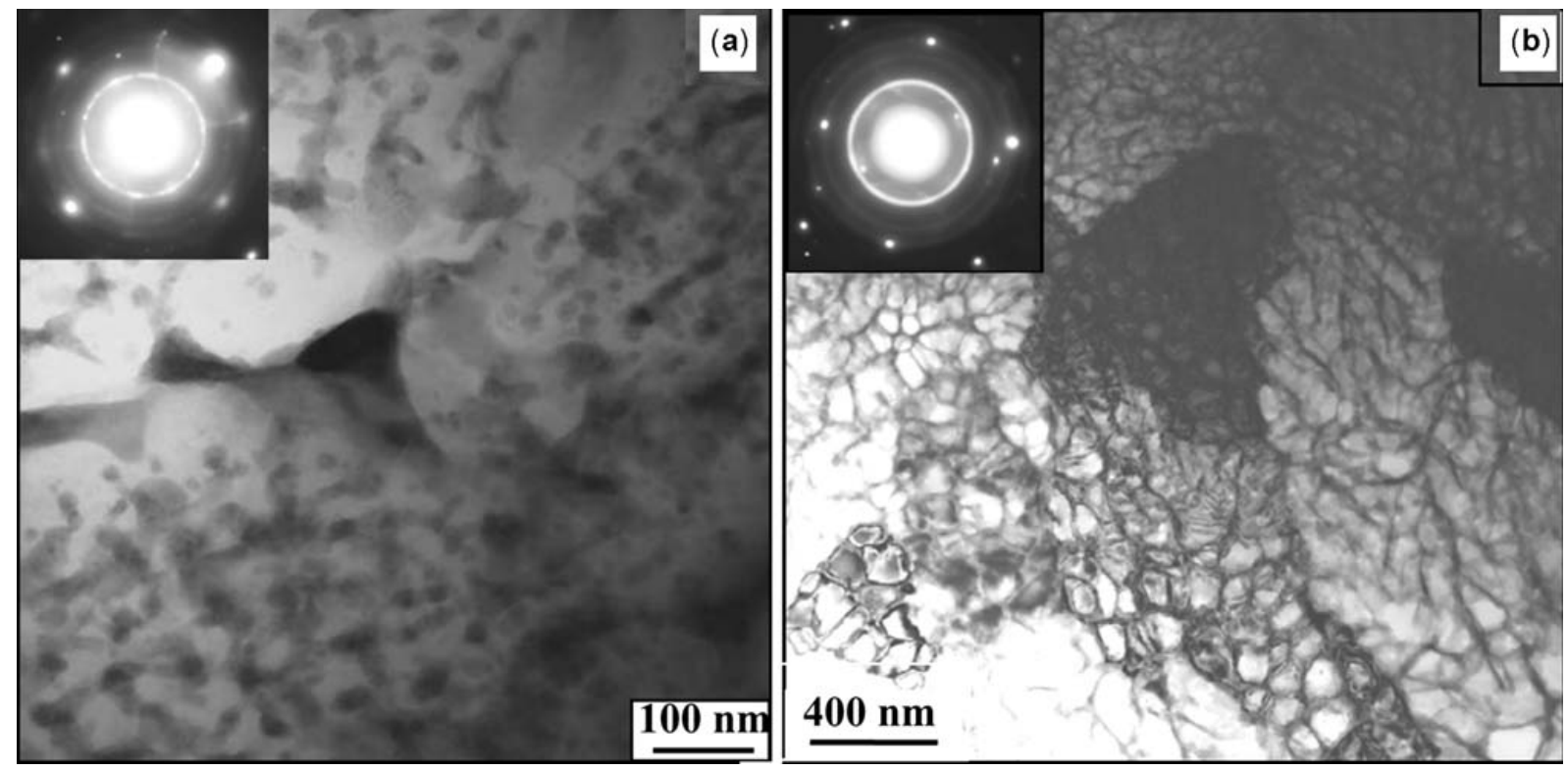

Figure 4. Bright field images of (a) Al-2.5\%Fe and (b) Al-5\%Fe alloy melt spun at a linear wheel speed of $40 \mathrm{~m} / \mathrm{s}$.

crease in Fe content of the alloy, as evident from the XRD patterns. The broadened XRD peaks indicate refinement of microstructure in these alloys due to the high cooling rate in melt spinning.

In the Al-Fe phase diagram (Kattner 1986), intermetallics with very complex crystal structures form and their most intense peaks are very close to the diffraction angle of $\mathrm{Al}(200)$ peak making it difficult to clearly identify them in the XRD analysis. To confirm the presence of the metastable phases in the melt spun alloys, a detailed TEM and electron diffraction (ED) study was carried out. Figures $4(\mathrm{a})$ and (b) show the microstructures of $\mathrm{Al}-2.5 \% \mathrm{Fe}$ and $\mathrm{Al}-5 \% \mathrm{Fe}$ alloys melt spun at a linear wheel speed of $40 \mathrm{~m} / \mathrm{s}$, respectively.

Dark regions of ultra-fine precipitates embedded in the bright $\alpha$-Al matrix were found in the melt spun $\mathrm{Al}-$ $2.5 \% \mathrm{Fe}$ alloy as shown in figure 4 (a). Most of the precipitates here are $<20 \mathrm{~nm}$ in size, though some bigger precipitates possibly at the grain boundaries were also present in the microstructure. The nature of precipitates could not be clearly identified in TEM, since the nanobeam diffraction patterns could not be obtained from these precipitates. However, indexing of the ED pattern in figure 5(a) indicated that these precipitates structurally resemble some nanoquasicrystalline (NQ) phase (Nayak et al 2006; Nayak 2007). There are several reports on the formation of quasicrystalline phase in binary alloys containing atleast $10 \%$ transition metal (TM) in Al (Shechtman et al 1984; Brendersky 1985; Brancel Hainey 1986; Fung et al 1986; Kelton 1993; Laissardiere et al 2005). However, quasicrystalline phase formation has not been reported so far in such dilute Al-TM alloys containing $\leq 2.5 \% \mathrm{Fe}$. Increasing the $\mathrm{Fe}$ content of the alloy to $5 \%$ made the solidification microstructure microcellular in nature, as shown in figure 4(b). The cells were 100 $150 \mathrm{~nm}$ in size. Cellular morphology is normally caused by the instability in diffusion layer surrounding the growing solid owing to the solute segregation during growth (Mullins and Seherka 1963). The ED pattern taken from the intercellular region shows the diffraction rings of typical quasicrystalline symmetry, as shown in the inset in figure 4(b), suggesting the presence of nano-quasicrystalline phase in this dilute binary alloy as well (Nayak et al 2006; Nayak 2007). The ED patterns in the inset of both figures 4 (a) and (b) show spotty diffraction rings from the $\alpha$-Al crystals, which were also present in the microstructure of the melt spun alloy, as also evident from the XRD patterns in figure 3 .

Interestingly, the microstructures of $\mathrm{Al}-10 \% \mathrm{Fe}$ and $\mathrm{Al}-15 \% \mathrm{Fe}$ alloys were found to be similar to that of $\mathrm{Al}-$ $5 \% \mathrm{Fe}$ alloy with nodular precipitates in $\mathrm{Al}$ matrix. In contrast, the melt spun Al-20\%Fe alloy did not form any metastable phase, as evidenced by the XRD pattern in figure 3. TEM investigation showed that melt spun Al$20 \% \mathrm{Fe}$ alloy formed dendrites of intermetallic phase, $\mathrm{Al}_{13} \mathrm{Fe}_{4}$, which is close to the composition of the equilibrium intermetallic phase, $\mathrm{Al}_{3} \mathrm{Fe}$ (Kattner 1986).

Finally, comparison of the microstructures of the Al-rich Al-Fe alloys of identical composition after MA and RSP shows they are entirely different. This divergence can originate from the difference in the mechanism of nonequilibrium phase formation in these two processing routes. In RSP all the alloying elements are in solution in the liquid prior to rapid solidification and these along with thermal disorder are partly frozen-in to yield the resultant phases. On the other hand, the sequence of dissolution 
and/or reaction of different alloying elements under the influence of deformation induced intermixing (Pabi and Murty 1996; Pabi et al 1998) and mechanical disorder induced in the MA process are likely to dictate the resultant phase evolution.

\section{Conclusions}

(I) Successful synthesis of nanocomposites of Al-Fe alloys containing $2 \cdot 5,5,10,15$ and $20 \%$ Fe was achieved by two most commonly used non-equilibrium processing routes viz. MA and RSP.

(II) After MA for $20 \mathrm{~h}$, alloys containing up to $10 \% \mathrm{Fe}$ showed the formation of supersaturated solid solution of $\mathrm{Fe}$ in $\mathrm{Al}$ form, while in the case of $\mathrm{Al}-20 \% \mathrm{Fe}$ alloy metastable $\mathrm{Al}_{5} \mathrm{Fe}_{2}$ intermetallic along with the super saturated solid solution was found.

(III) Formation of the equilibrium intermetallic phase, $\mathrm{Al}_{3} \mathrm{Fe}$, was not observed during MA and even after subsequent annealing at higher temperature $(673 \mathrm{~K})$, and the formation of the congruent melting intermetallic phase, $\mathrm{Al}_{5} \mathrm{Fe}_{2}$, was favoured.

(IV) Annealing at $673 \mathrm{~K}$ for $2 \mathrm{~h}$ after MA resulted in only marginal coarsening of the grain size of the intermetallics from $\sim 9 \mathrm{~nm}$ to $15-20 \mathrm{~nm}$ indicating the formation of true nanocomposite by this route.

(V) Some indication of a quasicrystalline related phase formation in the dilute binary Al-TM alloys containing 2.5 and $5 \% \mathrm{Fe}$ was noted.

(VI) Ultra-fine and possibly quasicrystalline precipitates, mostly $<20 \mathrm{~nm}$ in size, dispersed in the $\alpha$-Al matrix were found in the melt spun $\mathrm{Al}-2 \cdot 5 \% \mathrm{Fe}$ alloy. Increase in the Fe content of the alloy from 5-15\% made the solidification microstructure microcellular in nature. Melt spun Al-20\%Fe alloy formed dendrites of intermetallic phase, $\mathrm{Al}_{13} \mathrm{Fe}_{4}$, which is close to the composition of equilibrium intermetallic phase, $\mathrm{Al}_{3} \mathrm{Fe}$.

(VII) The difference in observed microstructure of the present $\mathrm{Al}-\mathrm{Fe}$ alloys obtained through the two non-equilibrium processing routes, i.e. MA and RSP, can be attributed to the difference in alloying mechanism in the two processes.

\section{Acknowledgements}

The present work is partly sponsored by the Department of Science and Technology (grant No. SR/S5/NMS1/2002). Authors are thankful to Peter Schubert-Bischoff and Dagmar Köpnick-Welzel, Hahn-Meitner-Institut (HMI), Berlin, for their help in preparing the TEM samples for this work. (SSN) acknowledges Prof. J Banhart, HMI, Berlin, and Prof. D -H Kim, Yonsei University, Seoul,
South Korea, for providing him support for carrying out part of this work.

\section{References}

Adam C M and Hogan L M 1972 J. Aust. Inst. Met. 1781

Badan B, Margini M and Zambon A 1996 Scr. Mater. 3513

Brancel P A and Heiney P A 1986 Phys. Rev. B33 7917

Brendersky L 1985 Phys. Rev. Lett. 551461

Datta M K, Pabi S K and Murty B S 2000a J. Mater. Res. 15 1429

Datta M K, Pabi S K and Murty B S 2000b J. Appl. Phys. 87 8393

De Boer F R, Room R, Nattens W C M, Miedema A R and Niessen A K 1989 Cohesion and structure (eds) F R de Boer and D G Pettifor (Amsterdam: North Holland) Vol. 1, p. 38

De Keijser T H, Langford J I, Mittemeijer E I and Vogels A B P 1982 J. Appl. Crystallogr. 15308

Fadeeva V I and Leonov A V 1996 Mater. Sci. Eng. A206 90

Froes F H, Senkov O N and Baburaj E G 2001 Mater. Sci. Eng. A301 44

Fung K K, Yang C Y, Zhou Y Q, Zhao J G, Zhan W S and Chen B G 1986 Phys. Rev. Lett. 582060

Huang B, Tokizane N, Ishihara K N, Shingu P H and Nasu S 1990 J. Non-Cryst. Solids 117/118 688

Kaloshkin S D, Tcherdynstev V V, Tomlin A I, Gunderov D V, Stolyarov V V, Baldokhin Y V, Brodova G I and Shelekhov E V 2002 Mater. Trans. JIM 432031

Kattner U R 1986 in Al-Fe, binary alloy phase diagrams (ed.) T B Massalski (Metals Park, Ohio: American Society for Metals) Vol. 1, p. 147

Kelton K F 1993 Int. Mater. Rev. 38105

Laissardiere G T, Nguyen-Manh D and Mayou D 2005 Prog. Mater. Sci. 50679

Mukhopadhyay D K, Suryanarayana C and Froes F H 1995 Metall. Mater. Trans. A26 1939

Mullins W W and Sekerka R F 1963 J. Appl. Phys. 35444

Nayak S S 2007 Synthesis and characterization of nanocrystalline intermetallics and nanocomposites of Al-TM alloys $(T M=T i, Z r, F e)$ prepared by non-equilibrium processing routes, $\mathrm{PhD}$ Thesis, Indian Institute of Technology, Kharagpur

Nayak S S, Kim D H, Pabi S K and Murty B S 2006 Trans. Ind. Inst. Met. 59193

Niu X P, Froyen L, Delaey L and Peytour C 1994 J. Mater. Sci. 293724

Pabi S K and Murty B S 1996 Mater. Sci. Eng. A214 146

Pabi S K, Das D, Mahapatra T K and Manna I 1998 Acta Mater. 463501

Riontino G and Zanada A 1994 Mater. Sci. Eng. A179-180 323

Senkov O N, Froes F H, Stolyarov V V, Valiev R Z and Liu J 1998 Scr. Mater. 381516

Shechtman D, Blech I, Gratias D and Cahn J W 1984 Appl. Phys. Lett. 531951

Tonejc A and Bonefasčié A 1969 Scr. Metall. 3145

Young R M K and Clyne T W 1981 Scr. Metall. 151211 